http://jmscr.igmpublication.org/home/ ISSN (e)-2347-176x ISSN (p) 2455-0450

crossref DOI: https://dx.doi.org/10.18535/jmscr/v8i1.147

Journal Of Medical Science And Clinical Research

IGM Publication

An Official Publication of IGM Publication

\title{
Comparison of V-Y advancement fasciocutaneous flaps and Gluteal perforator propeller flaps for reconstruction of sacral pressure sore
}

\author{
Authors \\ Dr T.V. Subha ${ }^{1}$, Dr R. Vivek MS, $\mathrm{MCh}^{2^{*}}$, Prof. J. Jaganmohan MS, $\mathrm{MCh}^{3}$ \\ ${ }^{1}$ Resident, Department of Plastic, Reconstructive and Facio-Maxillary Surgery, Madras Medical College, \\ Chennai-3 \\ ${ }^{2}$ Assistant Professor, Department of Plastic, Reconstructive and Facio-Maxillary Surgery, Madras Medical \\ College, Chennai-3 \\ ${ }^{3}$ Professor and Head of Department, Department of Plastic, Reconstructive and Facio-Maxillary Surgery, \\ Madras Medical College, Chennai-3 \\ *Corresponding Author
}

Dr R.Vivek

Assistant Professor, Department of Plastic, Reconstructive and Facio-Maxillary Surgery, Madras Medical

College, Chennai-3, India

\begin{abstract}
Introduction: Pressure sores are a common problem associated with great morbidity and cost. The most common site of occurrence is sacrum in bed ridden patients. Over the years several methods have been used to reconstruct sacral pressure sore. However, no consensus has been reached, regarding their definitive management. Gluteal fasciocutaneous flaps are commonly preferred, because they facilitate the preservation of the gluteal muscle integrity and muscle function and allow for revision in the event of recurrence. In recent years, the development of perforator flap surgery has increased the number of potential donor sites. Gluteal perforator (GP) propeller flap provides healthy tissue with a robust blood supply can be transferred freely without sacrificing the underlying muscle.

Aim and Objective: Comparative studies of GP flap and V-Y fasciocutaneous flap for sacral pressure sore are rarely reported in literature. The purpose of this retrospective study was to analyze the outcome and surgical complications of perforator and V-Y fasciocutaneous flaps and compare them.

Material and Methods: In this retrospective study data is collected from September 2017 to august 2019, 20 patients with stage IV sacral sores underwent reconstruction. In these 10 patients had gluteal perforator propeller flaps and 10 had V-Y advancement fasciocutaneous flaps done. Data collected are age, sex, comorbidity which caused sacral sore, operative time, defect size, time to heal.

Results: Effective analysis done between these two group shows there is no major difference in the outcome and complications in reconstructing sacral sore using either gluteal perforator propeller flap or $V$-Y advancement fasciocutaneous flap. But there are certain advantages in use of each of these flaps.

Conclusion: This retrospective study shows gluteal perforator propeller flap has more movement compared to $V$-Y advancement flap, so to reconstruct large defects $V$-Y flap from either side would be necessary. Perforator propeller flap requires periperforator dissection results in increased operative time. In case of recurrence re-advancement of $V$ - $Y$ flap can be done.

Keywords: $V-Y$ advancement flap, Gluteal perforator flap, sacral pressure sore.
\end{abstract}




\section{Introduction}

In general, wounds acquired from pressure over bony prominences are called as pressure sores ${ }^{(1)}$. Pressure sores are a common problem associated with great morbidity and cost. The most common site of occurrence is sacrum in bed ridden patients. Over the years several methods have been used to reconstruct sacral pressure sore. However, no consensus has been reached, regarding their definitive management. Loco regional fasciocutaneous and musculocutaneous flaps remain workhorse flaps as they can provide enough viable tissue for large defects. Gluteal fasciocutaneous flaps are commonly preferred, because they facilitate the preservation of the gluteal muscle integrity and muscle function and allow for revision in the event of recurrence. In recent years, the development of perforator flap surgery has increased the number of potential donor sites. Gluteal perforator propeller flap provides healthy tissue with a robust blood supply which can be transferred freely without sacrificing the underlying muscle.

\section{Aim and Objective}

Review of literature shows that there is no statistically significant difference with regard to recurrence or complication rates among musculocutaneous, fasciocutaneous and perforator flaps for pressure sore reconstruction. Comparative studies of GP flap and V-Y fasciocutaneous flap for sacral pressure sore are rarely reported in literature. The purpose of this retrospective study was to evaluate the differences in operative time, the duration of wound healing and the occurrence of surgical complications between perforator and V-Y fasciocutaneous flaps and to determine which procedure will be apt to reconstruct pressure ulcers in the sacral region.

\section{Material and Methods}

This retrospective study was performed inour Department from September 2017 to august 2019 by collecting data of 20 patients who were underwent flap reconstruction for stage IV sacral pressure sore. Spinal cord injury was the primary condition in all patients. 10 patients were treated with gluteal perforator propeller flap and 10 with V-Y advancement fasciocutaneous flap. The patients treated with other types of flap reconstruction and revised reconstructions were excluded.

\section{Surgical Procedure}

The surgical procedures are a standard technique that includes the thorough debridement of all necrotic, infectious tissues, pseudo bursa excision and removal of the sacral bony prominence. The perforator and V-Y advancement flaps are elevated above the gluteal muscle layer. In this study we used modified V-Y advancement flap (pacman). V-Y flap was used unilaterally or bilaterally according to the size of the defect. Y flap marking was done based on biogeometry. The limbs of the $\mathrm{V}$ were drawn as slightly curved convex lines, which made them broader than those of a conventional V-Y advancement flap. Skin incisions were carried down to the muscle fascia along the sides of the flaps. The upper and lower limbs of the flaps were elevated as but remained attached to the main flap. While giving inset two limbs are approximated to each other in unilateral flap or interdigitated in case of bilateral flaps (fig 1).

Fig 1: bilateral V-Y fasciocutaneous advancement flap

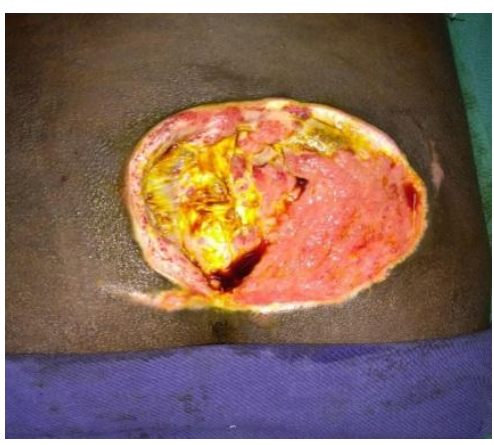

a) stage IV sacral sore 


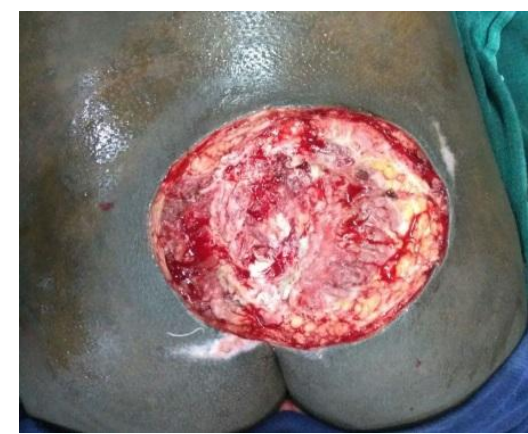

b) defect after debridement

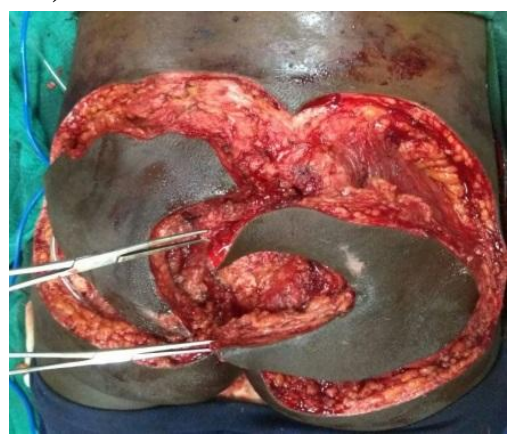

c) bilateral V-Y flap raised

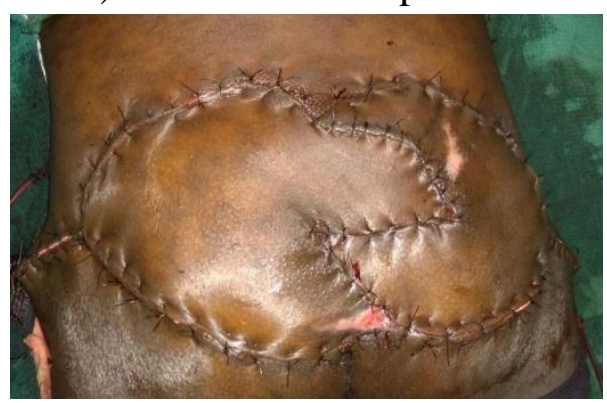

d) after flap inset

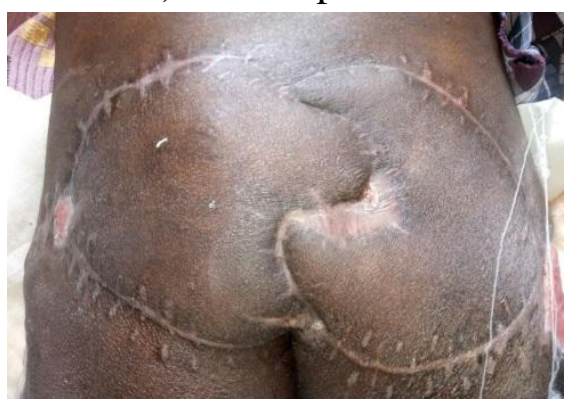

e) 3 months follow up

In gluteal perforator flap group, preoperative marking of perforators was done using hand held Doppler. Flap was raised based on either superior gluteal artery perforatoror inferior gluteal artery perforator which was determined by the site of defect and available donor tissue. Perforator flap marking was done according to biogeometry. First non-delineating incision was made and dissection was done above gluteal muscle plane till identifying the largest perforator. After that flap incision was completed and raised from distal to proximal side. To obtain propeller movement without kinking, periperforator dissection was done. Flap was propelled and inset was given. Donor site was closed primarily (fig 2). Suction drain was kept in all patients. Total avoidance of pressure on the flap for 2 weeks was carried out in both groups.

Data collected on patients include age; gender and co-morbidity for being bedridden were collected. Surgical details, including the defect size, operative time were recorded. Complications, including wound infection, dehiscence, flap necrosis (partial and total necrosis) and healing time were also recorded. Patients presented with the above mentioned complication were treated with drainage, antibiotic administration or debridement.

Fig 2: gluteal perforator flap - IGAP

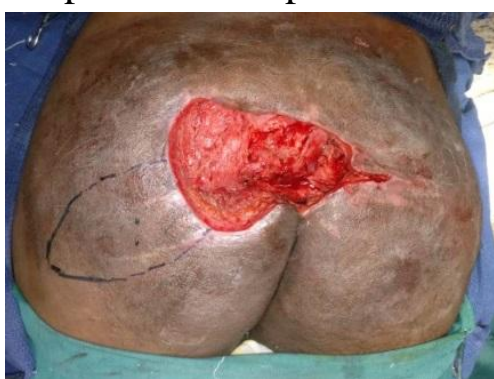

a) defect with flap marking

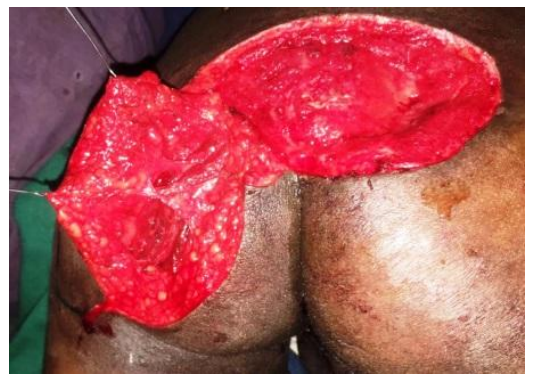

b) perforator identified

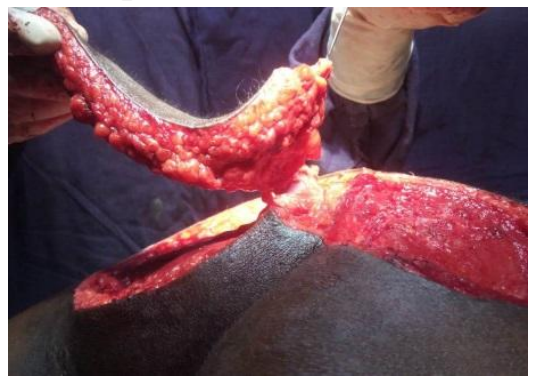

c) periperforator dissection done 


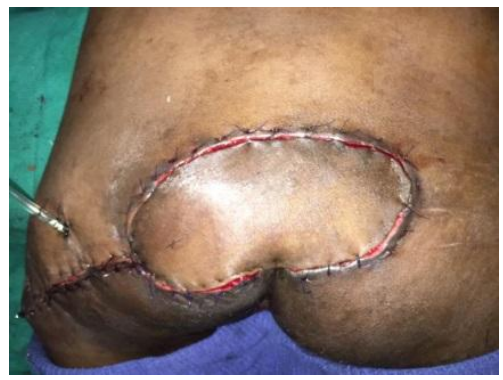

d) flap inset given

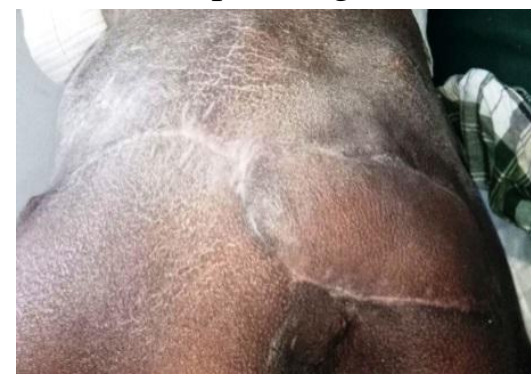

e) 3 months follow up

\section{Results}

In this study data of 20 patients with stage IV sacral pressure sore were collected. In this 10 patients underwent V-Y advancement fasciocutaneous flap and 10 patients underwent gluteal perforator propeller flap. The data collected shows there was no significant difference between two groups in age, sex and defect size (table1 and 2). Operative time is more in perforator group compared to $\mathrm{V}-\mathrm{Y}$ advancement group and it is due to tedious and meticulous periperforator dissection (chart 1).

Table 1: Details of V-Y advancement flap group

\begin{tabular}{|l|c|c|c|c|c|}
\hline s.no & AGE & SEX & $\begin{array}{c}\text { DEFECT SIZE } \\
(\mathrm{cms})\end{array}$ & FLAP DONE & $\begin{array}{c}\text { OPERATING } \\
\text { TIME(mins })\end{array}$ \\
\hline 1 & 45 & $\mathrm{M}$ & $4 \times 3$ & Single V-Y & 45 \\
\hline 2 & 29 & $\mathrm{M}$ & $5 \times 4$ & Single V-Y & 55 \\
\hline 3 & 36 & $\mathrm{~F}$ & $4 \mathrm{X} 3$ & Single V-Y & 60 \\
\hline 4 & 40 & $\mathrm{M}$ & $9 \mathrm{X} 6$ & Double V-Y & 110 \\
\hline 5 & 52 & $\mathrm{M}$ & $6 \mathrm{X} 5$ & Single V-Y & 45 \\
\hline 6 & 30 & $\mathrm{M}$ & $10 \mathrm{X} 8$ & Double V-Y & 120 \\
\hline 7 & 50 & $\mathrm{~F}$ & $6 \mathrm{X} 5$ & Single V-Y & 50 \\
\hline 8 & 28 & $\mathrm{M}$ & $5 \mathrm{X} 4$ & Single V-Y & 50 \\
\hline 9 & 48 & $\mathrm{M}$ & $5 \mathrm{X} 5$ & Single V-Y & 45 \\
\hline 10 & 55 & $\mathrm{M}$ & $8 \mathrm{X} 7$ & Double V-Y & 95 \\
\hline RANGE & $28-55$ & & & & $45-120$ \\
\hline MEDIAN & 43 & & & & 57 \\
\hline
\end{tabular}

Table 2: Details of gluteal perforator flap group

\begin{tabular}{|l|c|c|c|c|c|}
\hline S.NO & AGE & SEX & $\begin{array}{c}\text { DEFECT } \\
\text { SIZE } \\
(\mathrm{cms})\end{array}$ & $\begin{array}{c}\text { FLAP } \\
\text { DONE }\end{array}$ & $\begin{array}{c}\text { OPERATING } \\
\text { TIME(mins) }\end{array}$ \\
\hline 1 & 50 & $\mathrm{M}$ & $5 \mathrm{X} 4$ & SGAP & 90 \\
\hline 2 & 44 & $\mathrm{~F}$ & $10 \mathrm{X} 8$ & IGAP & 110 \\
\hline 3 & 29 & $\mathrm{M}$ & $4 \mathrm{X} 4$ & IGAP & 70 \\
\hline 4 & 38 & $\mathrm{~F}$ & $9 \mathrm{X} 7$ & SGAP & 80 \\
\hline 5 & 54 & $\mathrm{M}$ & $5 \mathrm{X} 4$ & IGAP & 60 \\
\hline 6 & 36 & $\mathrm{M}$ & $4 \mathrm{X} 3$ & SGAP & 70 \\
\hline 7 & 49 & $\mathrm{M}$ & $6 \mathrm{X} 7$ & SGAP & 65 \\
\hline 8 & 43 & $\mathrm{M}$ & $5 \mathrm{X} 4$ & SGAP & 85 \\
\hline 9 & 52 & $\mathrm{~F}$ & $8 \mathrm{X} 7$ & IGAP & 105 \\
\hline 10 & 26 & $\mathrm{M}$ & $5 \mathrm{X} 6$ & SGAP & 90 \\
\hline RANGE & $26-54$ & & & & $60-110$ \\
\hline MEDIAN & 44 & & & & 83 \\
\hline
\end{tabular}


Chart 1: bar chart predicting median operative time

\section{MEDIAN OPERATIVE TIME(mins)}

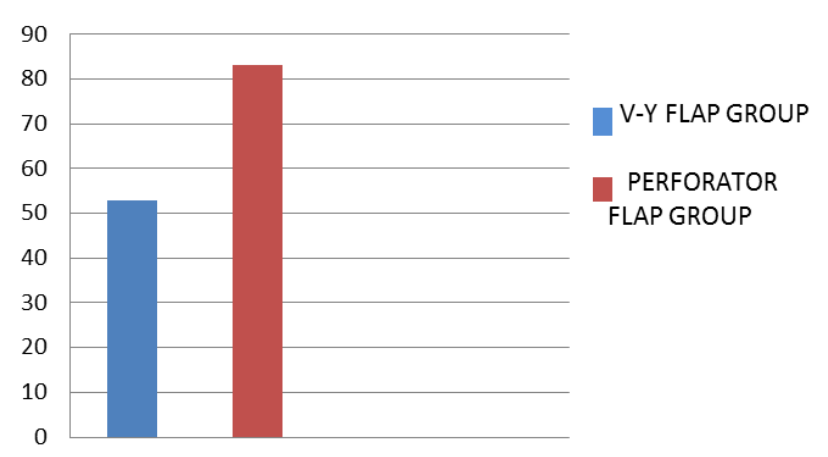

In post-surgical period, patients were observed for complications such as wound infection, dehiscence, flap necrosis, seroma formation and median healing time was also noted (table 4). In V-Y advancement group 2 patients developed wound infection, treated with antibiotics and settled; one patient developed seroma treated conservatively and 2 patients who developed wound dehiscence were treated with secondary suturing. In gluteal perforator flap group seroma collection occurred in 1 patient and was treated conservatively. Wound dehiscence in 1 patient was resutured. Two patients developed distal end epidermolysis for whom debridement was done and wound healed by secondary intention. Postsurgical complications were compared and there is not much difference between two groups.

Table 4: Comparison of surgical complications and healing time

\begin{tabular}{|l|c|c|c|}
\hline COMPLICATIONS & $\begin{array}{c}\text { V-Y ADVANCEMENT } \\
\text { GROUP }\end{array}$ & $\begin{array}{c}\text { PERFORATOR FLAP } \\
\text { GROUP }\end{array}$ & TREATMENT DONE \\
\hline SEROMA & 1 & 1 & CONSERVATIVE \\
\hline WOUND INFECTION & 2 & 1 & ANTIBIOTICS \\
\hline $\begin{array}{l}\text { WOUUND } \\
\text { DEHISCENCE }\end{array}$ & 2 & 2 & HESULRING \\
\hline $\begin{array}{l}\text { FLAP DISTAL END } \\
\text { EPIDERMOLYSIS }\end{array}$ & - & & $\begin{array}{c}\text { SECONDARY } \\
\text { INTENTION }\end{array}$ \\
\hline $\begin{array}{l}\text { MEDIAN HEALING } \\
\text { TIME(DAYS) }\end{array}$ & 22 & 20 & \\
\hline
\end{tabular}

\section{Discussion}

Musculocutaneous flaps have been the mainstay for treating sacral pressure sores because of their rich blood supply ${ }^{(2)}$. This technique causes donorsite morbidity, especially in ambulatory patients. Muscle seems more sensitive to pressure than skin. Additionally, the transferred muscle undergoes significant atrophic degeneration with time, usually 1 year postoperatively. In experimental studies, pressure-induced hypoxia can cause muscle necrosis without skin necrosis in musculocutaneous flaps ${ }^{(3)}$.Yamamoto et $\mathrm{al}^{(5)}$ prefers fasciocutaneous flap as first choice over musculocutaneous flap or muscle flaps for sacral pressure sore reconstruction. Park and park $^{(1)}$ suggested the use of bilateral V-Y advancement fasciocutaneous flaps for the closure of middlesize $(8-11 \mathrm{~cm})$ sacral defects as an easy and less invasive option. Akan and associates ${ }^{(6)}$ reported successful results with larger sacral defects $(22$ $\mathrm{cm})$ using the modified bilateral V-Y advancement (pacman) fasciocutaneous flap. Akan and sungur ${ }^{(10)}$ suggested The Pac Man flap is a safe procedure and may be preferable to the classic bilateral V-Y advancement because it decreases the tension along the closure line and breaks the central vertical scar into a zigzagged line. Large defects that are difficult to close with the conventional bilateral V-Y advancement procedure can be closed with ease by using this modified technique.

For the past few years, perforator flaps have gainedpopularity. Koshima et $\mathrm{al}^{(4)}$ reconstructed sacral pressure sores using GP flaps and confirmed the reliability of the blood supply by describing details of perforator distribution based on cadaver dissection. Perforator-based flaps result in decreased donor-site morbidity due to the 
preservation of muscles. The versatility of perforator-based flaps is especially highlighted by the reconstruction of pressure ulcers using freestyle pedicled perforator based flaps directly adjacent to sores at various sites ${ }^{(7)}$. Most important of all; long pedicles of GPs enable tissue mobilization up to $12 \mathrm{~cm}$ in distance and achieve tension-free closure ${ }^{(8)}$. The disadvantages of the perforator flap are anatomical variation in perforator distribution, more tedious intramuscular dissection and the need of surgical expertise ${ }^{(4)}$. They are also more susceptible tovenous congestion, due to kinking of the pedicleand unpredictable nature of the perforator venaecomitantes $^{(9)}$.

In our study, we had chosen V-Y advancement flap in patients who were having perforators distant from the defect, high chance of recurrence (poorly cared patient). Gluteal perforator flap had chosen in patients who were having perforator near the defect, well cared patients with least chance of recurrence and also depends on availability of surgical expertise. Variables such as operative time and defect size were comparable in these two groups. Operative time is more in perforator group compared to $\mathrm{V}-\mathrm{Y}$ advancement group and it is due to tedious and meticulous periperforator dissection. For larger defects reconstruction, when done with V-Y advancement, two flaps were needed which required more operating time than done with a single perforator flap. Surgical complications such as seromaformation, wound infection, wound dehiscence, flap distal end epidermolysis and median healing time are comparable and there is no difference between two groups.

\section{Conclusion}

V-Y advancement fasciocutaneous flap and gluteal perforator propeller flap can be considered as first line option for stage IV sacral pressure sore. Gluteal perforator propeller flap has more movement compared to V-Y advancement flap, so to reconstruct large defects using V-Y flap needs two flaps. V-Y advancement fasciocutaneous flap reconstructions can be performed without microsurgical dissection, and re-advancement is feasible in case of recurrence. Recurrence in perforator flap group can only be managed with perforator flaps or fasciocutaneous flaps from the contralateral side.

Conflicts of Interest: No conflicts declared.

\section{References}

1. Park C. and Park B.Y.: Fasciocutaneous $\mathrm{V}-\mathrm{Y}$ advancement flap for repair of sacral defects. Ann. Plast. Surg., 21: 23-26, 1988

2. Ger R. The surgical management of decubitus ulcers by muscle transposition. Surgery 1971;69:106e10.

3. Sameem M, Au M, Wood T, et al. A systematic review of complication and recurrence rates of musculocutaneous, fasciocutaneous, and perforator-based flaps for treatment of pressure sores. PlastReconstrSurg 2012;130:67e77.

4. Koshima I, Moriguchi T, Soeda S, et al. The gluteal perforator based flap for repair of sacral pressure sores. PlastReconstrSurg 1993;91:678e83.

5. Yamamoto Y, Ohura T, Shintomi Y, et al. Superiority of the fasciocutaneous flap in reconstruction of sacral pressure sores. Ann Plast Surg 1993;30:116-121

6. Akan I’M, Ulusoy MG, Bilen BT, Kapucu MR. Modified bilateral advancement flap: the slide-in flap. Ann PlastSurg 1999;42:545-548

7. Yang CH, Kuo YR, Jeng SF, Lin PY. An ideal method for pressure sore reconstruction: A freestyle perforatorbased flap. Ann Plast Surg. 2011;66:179184

8. Meltem C, Esra C, Hasan F, et al. The gluteal perforator based flap in repair of pressure sores. $\mathrm{Br} \quad \mathrm{J}$ PlastSurg 2004;57:342e 7

9. Lee BT, Lin SJ, Bar-Meir ED, Borud LJ, Upton J. Pedicled perforator flaps: A new 
principle in reconstructive surgery. Plast Reconstr Surg. 2010;125:201-208.

10. Akan I'M, Sungur N, O* zdemi r R, Kilinc, $\mathrm{H}, \mathrm{S}$, enso"z O" . "Pac man" flap forclosure of pressure sores. Ann Plast Surg 2001;46:421-425. 